Pesq. Vet. Bras. 37(11):1307-1312, novembro 2017 DOI: 10.1590/S0100-736X2017001100018

\title{
Circulação de Rickettsias do Grupo da Febre Maculosa em cães no entorno de Unidades de Conservação Federais do estado do Rio de Janeiro: evidência sorológica e fatores associados ${ }^{1}$
}

\author{
Sabrina D.E. Campos ${ }^{2 *}$, Nathalie C. da Cunha ${ }^{3}$, Camila S.C. Machado ${ }^{2}$, Tatiana V.T. \\ de Souza ${ }^{2}$, Ana Beatriz M. Fonseca ${ }^{4}$, Adriano Pinter ${ }^{5}$, Adivaldo H. da Fonseca ${ }^{6}$ \\ e Nádia R.P. Almosny ${ }^{2}$
}

\begin{abstract}
Campos S.D.E., Cunha N.C., Machado C.S.C., Souza T.V.T., Fonseca A.B.M., Pinter A., Fonseca A.H. \& Almosny N.R.P. 2017. [Spotted Fever Group Rickettsiae in dogs at the surroundings of Conservation Units in the state of Rio de Janeiro: serological survey and associated factors.] Circulação de Rickettsias do Grupo da Febre Maculosa em cães no entorno de Unidades de Conservação Federais do estado do Rio de Janeiro: evidência sorológica e fatores associados. Pesquisa Veterinária Brasileira 37(11):1307-1312. Departamento de Patologia e Clínica Veterinária, Universidade Federal Fluminense, Rua Vital Brazil Filho 64, Santa Rosa, Niterói, RJ 24230-340, Brazil. E-mail: s.destri@gmail.com

Diseases caused by Rickettsiae have wide distribution and are associated with arthropods. Rickettsia rickettsii is the most pathogenic species of the Spotted Fever Group (SFG) and responsible for the Brazilian Spotted Fever. In the southeast the disease is endemic and serological surveys have demonstrated the presence of antibodies to SFG antigens in dogs, reinforcing the participation of the dog as sentinels. The main vectors are Amblyom$m a$ ticks, for which hosts are often wildlife animals. The aim of this study was to evaluate the presence of SFG Rickettsiae in the surroundings of Conservation Units (UC) at the state of Rio de Janeiro by Indirect Immunofluorescence Assay in dogs, and determine associated factors. Serum samples of 155 dogs were tested, with $16.1 \%$ of the seropositive animals at least to one of the antigens tested. There was an association between seroreactivity dogs and access to rainforest fragments; lack of veterinary care assistance; lack of actions against ticks; and family income up to two minimum salaries. Dogs with this profile had a higher chance of being exposed to SFG Rickettsiae. According to logistic regression, not going to rainforest areas was considered a protective factor for the dog along with the existence of veterinary care assistance and treatment against ticks. It was concluded that the SFG pathogens are present in the surroundings of UC studied, and possibly both $R$. rickettsii and $R$. parkeri are infecting dogs, since the animals showed exposure to both agents. We emphasize the participation of the veterinary and the adoption of the tick control measures as tools in preventing rickettsial infection.
\end{abstract}

INDEX TERMS: Spotted fever, Rickettsiae, dogs, Conservation Units, Rio de Janeiro, immunofluorescence, Rickettsia rickettsii, Rickettsia parkeri, serology, Odds Ratio.

\footnotetext{
${ }^{1}$ Recebido em 3 de abril de 2016.

Aceito para publicação em 6 de janeiro de 2017.

${ }^{2}$ Departamento de Patologia e Clínica Veterinária, Universidade Federal Fluminense (UFF), Rua Vital Brazil Filho 64, Santa Rosa, Niterói, RJ 24230340, Brasil. *Autor para correspondência: s.destri@gmail.com

${ }^{3}$ Departamento de Saúde Coletiva Veterinária e Saúde Pública, UFF, Rua Vital Brazil Filho 64, Santa Rosa, Niterói, RJ 24230-340, Brasil. E-mail: nathalie.cunha@gmail.com
}

\footnotetext{
${ }^{4}$ Instituto de Matemática e Estatística, UFF, Rua Mário Santos Braga s/n, 7 o andar, Centro, Niterói, RJ 24020-140, Brasil. E-mail: abmfonseca@id.uff.br

${ }^{5}$ Superintendência de Controle de Endemias, Avenida Paula Souza 166, Centro, São Paulo, SP 01027-000,Brasil. E-mail: adrianopinter@ gmail.com

${ }^{6}$ Departamento de Epidemiologia e Saúde Pública, Universidade Federal Rural do Rio de Janeiro (UFRRJ), Seropédica, RJ 23890-970, Brasil. E-mail: adivaldofonseca@yahoo.com
} 
RESUMO.- Doenças causadas por rickettsias tem ampla distribuição geográfica e estão associadas a artrópodes hematófagos. Rickettsia rickettsii é espécie mais patogênica do Grupo da Febre Maculosa (GFM) e responsável pela Febre Maculosa Brasileira. No sudeste do país a doença é endêmica e inquéritos sorológicos tem demonstrado presença de anticorpos para antígenos do GFM em cães, reforçando a participação do cão como sentinela. Os principais vetores são carrapatos do gênero Amblyomma, cujos hospedeiros são, muitas vezes, animais de vida silvestre. Assim, objetivou-se avaliar a circulação de rickettsias do GFM no entorno de Unidades de Conservação (UC) no Rio de Janeiro por meio da Imunofluorescência Indireta em cães, além de determinar os fatores associados. Amostras de soro de 155 cães foram testadas, sendo $16,1 \%$ dos animais sororreagentes pelo menos a um dos antígenos testados. Houve associação entre a sororreatividade dos cães e o acesso à mata; falta de assistência médico-veterinária; falta de medidas contra carrapatos; e renda familiar do responsável de até dois salários mínimos. Cães com este perfil apresentaram maior chance de serem expostos aos agentes do GFM. De acordo com o modelo de regressão logística, não frequentar áreas de mata foi considerado um fator de proteção para o cão, juntamente com possuir acompanhamento médico-veterinário e receber medidas contra carrapatos. Concluiu-se que patógenos do GFM circulam no entorno das UC estudadas, sendo possível que $R$. rickettsii e $R$. parkeri infectem cães, uma vez que os animais demonstraram exposição aos dois agentes. Ressalta-se a participação do veterinário e a adoção de medidas de combate a carrapatos como ferramentas na prevenção da infecção rickettsial.

TERMOS DE INDEXAÇÃO: Rickettsias, febre maculosa, cães, Unidades de Conservação, Rio de Janeiro, imunofluorescência indireta, Rickettsia rickettsii, Rickettsia parkeri, sorologia, razão de chances.

\section{INTRODUÇÃO}

Rickettsia rickettsii é a principal bactéria responsável pela Febre Maculosa, uma doença transmitida por vetores artrópodes relatada em humanos de diferentes países do continente americano, incluindo ao menos Estados Unidos da América (EUA), México, Panamá, Costa Rica e Brasil, país onde esta doença vem sendo chamada de Febre Maculosa Brasileira (FMB) (Lemos et al. 2001, Chapman et al. 2006, Estripeaut et al. 2007, Hun et al. 2008, Parola et al. 2013). A Imunofluorescência Indireta (IFI) é recomendada para triagem e diagnóstico da FMB, pois constitui teste acessível de alta sensibilidade e especificidade (Lemos et al. 2001, Brouqui et al. 2004). No Brasil, 1141 casos humanos confirmados pela IFI foram notificados entre os anos de 2007 e 2015, sendo 61,3\% (699/1141) na região sudeste, especialmente nos estados de São Paulo (43,2\%, 493/1141), Minas Gerais $(8,2 \%, 93 / 1141)$ e Rio de Janeiro $(7,2 \%$, 82/1141) (Brasil 2015).

Outro importante agente do gênero Rickettsia e do Grupo da Febre Maculosa (GFM), Rickettsia parkeri, vem sendo associado à doença humana (Whitman et al. 2007, Romer et al. 2011, Portillo et al. 2013, Kaskas et al. 2014), causan- do ponto necrótico (tache noire) e febre leve, mais branda do que na infecção por $R$. rickettsii (Whitman et al. 2007, Paddock et al. 2008, Cragun et al. 2010). Somado a isso, desde 2010 vem sendo investigada uma rickettsiose humana no bioma de Mata Atlântica Brasileira, cujo paciente apresentou quadro febril e presença de tache noire, e cuja bactéria responsável foi denominada $R$. parkeri cepa Mata Atlântica (Sabatini et al. 2010, Spolidorio et al. 2010).

Os cães podem permanecer próximos tanto do homem quanto das áreas habitadas pelo vetor e pelos hospedeiros amplificadores das bactérias do gênero Rickettsia, demonstrando nesses locais altos títulos de anticorpos anti- $R$. rickettsii, o que tem permitido que os cães sejam considerados sentinelas na epidemiologia da FMB (Cardoso et al. 2006, Cunha et al. 2014). Nesse contexto, o uso de testes sorológicos para a detecção de anticorpos contra antígenos do GFM em cães tem sido relatado em diferentes estados brasileiros, em especial na região sudeste do país (Horta et al. 2007, Pinter et al. 2008, Milagres et al. 2010, Pacheco et al. 2011, Cunha et al. 2014).

Entretanto, até o presente momento, não há relatos de estudos sorológicos avaliando a razão de chances e os fatores associados à infecção por espécies do gênero Rickettsia, do GFM, em cães de residências adjacentes a Unidades de Conservação (UC) Federais. As UC geridas pelo Instituto Chico Mendes de Conservação da Biodiversidade (ICMBio) são áreas de rica biodiversidade divididas em Proteção Integral e Uso Sustentável. As UC de Proteção Integral tem objetivo de preservar a natureza e diminuir a interferência humana sobre ela, enquanto as UC de Uso Sustentável tem objetivo de conciliar a conservação da natureza com a exploração de parte dos recursos naturais, de forma social e economicamente viável.

Considerando, 1) o impacto zoonótico da FMB; 2) a possibilidade de cães como sentinelas; 3) o contato de cães residentes no entorno de UC com a fauna silvestre própria do local; 4) a expansão das atividades ocupacionais e de lazer, permitindo maior interação do homem com o ambiente silvestre; e 5) a exposição aos vetores da FMB pelos aspectos acima abordados, o objetivo do presente estudo foi avaliar a circulação de rickettsias do GFM no entorno de UC federais geridas pelo ICMBio no estado RJ por meio da evidência sorológica em cães, além de identificar a razão de chances e os fatores associados para os cães domiciliados em residências adjacentes às UC avaliadas.

\section{MATERIAL E MÉTODOS}

O presente estudo foi aprovado pelo Comitê de Ética no Uso de Animais da Universidade Federal Fluminense, recebendo documento número 438, e pelo Instituto Brasileiro de Meio Ambiente e Recursos Naturais Renováveis por meio do Sistema de Autorização e Informação da Biodiversidade, recebendo autorização para atividades com finalidade científica em Unidades de Conservação número 40330-2.

Áreas de estudo. Foram selecionados municípios do estado do RJ contendo UC geridas pelo ICMBio, de áreas fronteiriças ou com registro de surtos de FMB, sendo incluídas três Unidades de Proteção Integral (Parque Nacional do Itatiaia, Parque Nacional da Tijuca e Parque Nacional da Serra dos Órgãos) e duas Unidades de Uso Sustentável (Área de Relevante Interesse Ecológico da 
Floresta da Cicuta e Reserva Particular do Patrimônio Nacional Fazenda São Benedito).

O Parque Nacional do Itatiaia (PNI), situado na Serra da Mantiqueira, apresenta relevo de montanhas, com altitude de 600 a 2791 metros, com presença de nascentes e cursos de água em toda a sua extensão. A parte baixa recebe o maior fluxo de turistas do PNI. Já o Parque Nacional da Tijuca (PNT) compreende um fragmento de Mata Atlântica em estágio de regeneração, ocupando aproximadamente 3,5\% da área do município do RJ. 0 PNT recebe em média dois milhões de visitantes ao ano, sendo a UC federal mais visitada do Brasil. 0 acesso principal deve ser realizado pela estrada do Alto da Boa Vista até o Setor Floresta da Tijuca. Finalmente, o Parque Nacional da Serra dos Órgãos (Parnaso), comumente visitado para a prática de esportes de montanha, encontra-se situado na região serrana do RJ, entre as cidades de Teresópolis e Petrópolis, possuindo entrada principal na área urbana de Teresópolis, sobre o Rio Paquequer.

A cidade de Barra Mansa possui $85 \%$ da Área de Relevante Interesse Ecológico (ARIE) da Floresta da Cicuta, e a cidade de Volta Redonda engloba 15\% dessa UC, cujo bioma predominante é a Mata Atlântica e que está localizada entre as Serras do Mar e da Mantiqueira. A última UC utilizada neste estudo foi a Fazenda São Benedito, uma Reserva Particular do Patrimônio Natural (RPPN) situada no município de Rio Claro, RJ, que alberga em seu interior uma área de soltura de animais silvestres apreendidos.

Foram incluídos todos os cães com idade mínima de cinco meses, independente de sexo, raça, idade e estado clínico, domiciliados nas residências adjacentes ao limite geográfico da UC, configurando um estudo observacional transversal com amostra de conveniência. Considerando estudos prévios acerca da soroprevalência em cães de diferentes localidades brasileiras, porém fora de foco ativo da FMB (Lemos et al. 1996, Labruna et al. 2007, Milagres et al., 2010), o corrente estudo estimou prevalência de 10\% para o cálculo amostral que determinasse resultado confiável da prevalência $(\mathrm{P})$ utilizando a fórmula matemática $\mathrm{n}=\mathrm{P}(1-\mathrm{P})(1,96 /$ $\Delta)^{2}$ (Sampaio 1998), resultando em amostra mínima de 138 cães.

Obtenção e processamento das amostras. Os responsáveis pelos cães foram informados sobre a natureza do estudo, autorizando a obtenção das amostras biológicas mediante assinatura do termo de consentimento livre e esclarecido. Posteriormente, procedeu-se coleta única de cada animal, no período entre setembro de 2013 e novembro de 2014, totalizando 155 cães. Foram obtidos aproximadamente $3,0 \mathrm{~mL}$ de sangue, acondicionados em frasco sem anticoagulante. No momento da coleta, efetuou-se o preenchimento de um questionário contendo informações a respeito do local de estudo; sexo; idade; acesso a áreas de mata, pastagem e coleções hídricas no interior da UC, regularidade de assistência médico-veterinária; adoção de medidas de combate e/ ou prevenção contra carrapatos; e renda familiar do responsável pelo animal.

As amostras foram centrifugadas para a extração do soro, sendo então procedida a IFI, utilizando lâminas de 12 orifícios sensibilizadas com dois diferentes antígenos ( $R$. rickettsii, cepa Taiaçu e R. parkeri, cepa AT-24). Amostras de soro sabidamente negativas e positivas de cães naturalmente infectados procedentes do município de Resende-RJ foram utilizadas como controles em cada lâmina. A IFI foi realizada conforme Horta et al. (2007), utilizando anti-IgG de cão conjugado com isotiocianato de fluoresceína (FITC) produzido em coelho (Sigma-Aldrich Brasil Ltda ${ }^{\circledR}$, São Paulo, São Paulo, Brasil). As amostras de soro foram diluídas em Solução Tampão Salino Fosfatado (PBS) até a titulação inicial de 1:64 e então aplicadas aos orifícios das lâminas, incubadas e lavadas em PBS. Após a secagem das lâminas, foi adicionado o anticorpo conjugado, seguindo novas etapas de incubação e lavagem.
Posteriormente, foi adicionada glicerina tamponada para montagem das lâminas com lamínula e as mesmas foram observadas em microscópio de fluorescência, com aumento de 400x.

Análise estatística. Após a obtenção dos resultados, foi calculada a frequência de cães com reação sorológica positiva e as variáveis foram armazenadas em planilha eletrônica (EXCEL 2007, Microsoft ${ }^{\circledR}$, São Paulo, São Paulo, Brasil), sendo posteriormente analisadas pelos testes de Qui-Quadrado, Exato de Fisher (Statistical Package for Social Science, SPSS, SPSS Inc., EUA, versão 17) e Odds Ratio (BioEstat, versão 5.0, Instituto Mamirauá, Belém, Pará, Brasil) (AYRES et al., 2007) para a razão de chances, com nível de significância de $95 \%$. As variáveis que apresentaram $\mathrm{p}<0,2$ no teste de Qui-Quadrado (Zar 1999) foram selecionadas para análise multivariada utilizando o modelo de regressão logística múltipla pelo método "stepwise forward" condicional. Foram adotados 0,05 como probabilidade de entrada e 0,10 como probabilidade de saída. As análises foram processadas com auxílio do programa SPSS.

\section{RESULTADOS}

Os resultados não foram suficientes para identificação da espécie do gênero Rickettsia, mas revelaram circulação de agentes do GFM, uma vez que as espécies deste grupo compartilham antígenos de superfície que ocasionam reações positivas com soros heterólogos. A análise pelo teste Exato de Fisher demonstrou que houve associação $(p<0,05)$ entre a sororreatividade dos cães para os dois antígenos testados pela IFI, assim, todas as amostras com título mínimo de 1:64 foram consideradas reagentes anti-Rickettsia GFM, resultando em 16,1\% (25/155) de cães reagentes na IFI anti- $R$. rickettsii e/ou anti- $R$. parkeri (Quadro 1).

Dentre os cães avaliados, 25,8\% (40) residiam no entorno do Parnaso, 24,5\% (38) residiam no entorno do PNI, $19,3 \%$ (30) residiam no entorno do PNT, 16,8\% (26) residiam no entorno da ARIE e 13,6\% (21) residiam no entorno da RPPN, não sendo observada diferença significativa entre os locais estudados e a frequência de animais reagentes (Quadro 2). Houve associação $(\mathrm{p}<0,05)$ entre a faixa etária e a frequência de animais reagentes pela IFI, sendo encontrados mais animais com reação sorológica entre três e sete anos de idade (Quadro 2).

A avaliação do questionário aplicado em colaboração com os responsáveis pelos cães revelou que animais reagentes pela IFI e com livre acesso à mata, pastos e leitos de água no interior das UC estudadas totalizaram $31,9 \%$. Houve diferença significativa $(\mathrm{p}<0,05)$ na sororreatividade entre os animais com e sem hábito de acessar regiões de mata, pastagem e leitos de água, sendo este hábito considerado

Quadro 1. Frequência de cães amostrados no presente estudo conforme resultado da Imunofluorescência Indireta para Rickettsia rickettsii e/ou Rickettsia parkeri. Amostras de soro obtidas no estado do Rio de Janeiro, 2013 e 2014

\begin{tabular}{lcccc}
\hline Rickettsia parkeri & \multicolumn{4}{c}{ Rickettsia rickettsii } \\
\cline { 2 - 5 } & $\begin{array}{c}\text { Reagentes } \\
(\%)\end{array}$ & $\begin{array}{c}\text { Não Reagentes } \\
(\%)\end{array}$ & Total & p-valor \\
\hline Reagentes (\%) & $5(3,2 \%)$ & $10(6,5 \%)$ & $15(9,7 \%)$ & $0,007^{a}$ \\
Não Reagentes (\%) & $10(6,5 \%)$ & $130(83,8 \%)$ & $140(90,3 \%)$ & \\
Total & $15(9,7 \%)$ & $140(90,3 \%)$ & $155(100 \%)$ & -
\end{tabular}

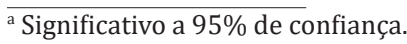


Quadro 2. Frequência absoluta, frequência relativa e razão de chances, odds ratio, de acordo com a sorreatividade de cães pela Imunofluorescência Indireta para detecção de anticorpos do tipo IgG anti-Rickettsia rickettsii e/ou anti-Rickettsia parkeri, para as variáveis obtidas por meio de questionário. Amostras de soro obtidas no estado do Rio de Janeiro, 2013 e 2014

\begin{tabular}{|c|c|c|c|c|c|}
\hline Variável & $\begin{array}{c}\text { Animais } \\
\text { Amostrados }\end{array}$ & $\begin{array}{c}\text { Animais } \\
\text { Reagentes (\%) }\end{array}$ & p-valor & Odds Ratio & $\begin{array}{c}\text { Intervalo de } \\
\text { Confiança (95\%) }\end{array}$ \\
\hline \multicolumn{6}{|l|}{ Unidade de Conservação } \\
\hline Parnaso $^{\mathrm{b}}$ & 40 & $3(7,5 \%)$ & 0,0570 & - & - \\
\hline $\mathrm{PNI}^{\mathrm{c}}$ & 38 & $7(18,4 \%)$ & & & \\
\hline $\mathrm{PNT}^{\mathrm{d}}$ & 30 & $5(16,7 \%)$ & & & \\
\hline ARIE $^{\mathrm{e}}$ & 26 & $5(19,2 \%)$ & & & \\
\hline $\mathrm{RPPN}^{\mathrm{f}}$ & 21 & $5(23,8 \%)$ & & & \\
\hline \multicolumn{6}{|l|}{ Idade } \\
\hline $0-36$ meses & 60 & $5(8,3 \%)$ & $0,0300^{\mathrm{a}}$ & _- & _- \\
\hline $3-7$ anos & 65 & $11(16,9 \%)$ & & & \\
\hline$>8$ anos & 30 & $9(12,5 \%)$ & & & \\
\hline \multicolumn{6}{|l|}{ Sexo } \\
\hline Macho & 83 & $16(19,3 \%)$ & 0,2809 & 1,6716 & $0,6891-4,0550$ \\
\hline Fêmea & 72 & $9(12,5 \%)$ & & & \\
\hline \multicolumn{6}{|l|}{$\begin{array}{l}\text { Mata, pastagem e } \\
\text { coleção hídrica }\end{array}$} \\
\hline Sim & 69 & $22(31,9 \%)$ & $<0,0001^{\text {a }}$ & 12,9504 & $3,6799-45,5753$ \\
\hline Não & 86 & $3(3,5 \%)$ & & & \\
\hline \multicolumn{6}{|l|}{ Renda familiar } \\
\hline Até 2 salários mínimosg & 70 & $19(27,1 \%)$ & $0,0017^{\mathrm{a}}$ & 4,7190 & $1,7639-12,6243$ \\
\hline Acima de 2 salários mínimosg & 82 & $6(7,3 \%)$ & & & \\
\hline \multicolumn{6}{|l|}{$\begin{array}{l}\text { Combate/prevenção } \\
\text { de carrapatos }\end{array}$} \\
\hline Não & 48 & $16(33,3 \%)$ & $0,0002^{\mathrm{a}}$ & 5,4444 & $2,1938-13,5116$ \\
\hline Sim & 107 & $9(8,4 \%)$ & & & \\
\hline \multicolumn{6}{|l|}{ Assistência Veterinária } \\
\hline Não & 87 & $22(25,3 \%)$ & $0,0003^{\mathrm{a}}$ & 7,3333 & $2,0919-25,7070$ \\
\hline Sim & 68 & $3(4,4 \%)$ & & & \\
\hline
\end{tabular}

${ }^{\text {a }}$ Significativo a 95\% de confiança, ${ }^{\mathrm{b}}$ Parque Nacional da Serra dos Órgãos, ${ }^{\mathrm{c}}$ Parque Nacional do Itatiaia, ${ }^{\mathrm{d}}$ Parque Nacional da Tijuca, ${ }^{\mathrm{e}}$ Área de Relevante Interesse Ecológico Floresta da Cicuta, ${ }^{\mathrm{f}}$ Reserva Particular do Patrimônio Natural, ${ }^{\mathrm{g}}$ Valor do salário mínimo brasileiro no ano de 2013: R\$ 678,00.

Quadro 3. Fatores de proteção contra Rickettsia spp. estimados por regressão logística múltipla em cães. Amostras de soro obtidas no estado do Rio de Janeiro, 2013 e 2014

\begin{tabular}{lccc}
\hline Variável & p-valor & Odds Ratio & $\begin{array}{c}\text { Intervalo de } \\
\text { Confiança (95\%) }\end{array}$ \\
\hline $\begin{array}{l}\text { Mata, pastagem e coleção hídrica } \\
\text { Assistência Veterinária }\end{array}$ & 0,000 & 0,052 & $0,013-0,205$ \\
$\begin{array}{l}\text { Combate/prevenção } \\
\text { de carrapatos }\end{array}$ & 0,032 & 0,438 & $0,206-0,930$ \\
Renda familiar 1 $^{\text {a }}$ & 0,003 & 5,546 & $1,823-16,875$ \\
Renda familiar 2 $^{\text {b }}$ & 0,019 & 0,176 & $0,041-0,753$ \\
& 0,195 & 0,409 & $0,106-1,580$
\end{tabular}

${ }^{a}$ Renda familiar entre dois e quatro salários mínimos, ${ }^{\mathrm{b}}$ Renda familiar acima de quatro salários mínimos.

fator de exposição para o cão (Quadro 2). Ainda, 56,1\% dos cães amostrados não possuíam assistência médico-veterinária regular, sendo considerada assistência regular aquela realizada pelo menos uma vez por ano. Destes, $25,3 \%$ apresentaram reação sorológica na IFI, enquanto dos animais que eram regularmente acompanhados por médico veterinário, apenas 4,4\% apresentaram reação sorológica, havendo diferença significativa $(\mathrm{p}<0,05)$ entre eles (Quadro 2). Entre os cães cujos responsáveis não utilizavam nenhuma medida de combate e/ou proteção contra carrapatos, $33,3 \%$ foram reagentes na IFI, havendo diferença significativa $(p<0,05)$ entre estes e os cães cujos responsáveis ado- tavam medidas de combate e/ou proteção para carrapatos (Quadro 2). Houve associação $(\mathrm{p}<0,05)$ entre a frequência de animais reagentes a renda familiar do responsável pelo animal, sendo observada maior frequência $(27,1 \%)$ entre os cães cujos responsáveis apresentaram renda familiar igual ou inferior a dois salários mínimos (Quadro 2).

A razão de chances, Odds Ratio, demonstrou que a chance de exposição aos organismos do GFM foi entre cinco e sete vezes maior para os cães cujo perfil incluiu o hábito de adentrar nas UC apresentando contato com áreas de mata, pastagem e coleções hídricas, não ter acompanhamento médico-veterinário ao menos uma vez por ano, não receber qualquer medida contra a infestação por carrapatos e pertencer a famílias com renda igual ou inferior a dois salários mínimos (Quadro 2).

As variáveis utilizadas para regressão logística múltipla $(\mathrm{p}<0,2)$ foram faixa etária; acesso à mata, pastagens e leitos de água; assistência médico-veterinária regular; uso de medidas de combate e/ou prevenção contra carrapatos e renda familiar do responsável pelo cão. Observou-se, com significância de 95\% (Quadro 3), que não ter acesso aos locais de mata, pastagens e leitos de água nas UC, receber acompanhamento veterinário regular e receber alguma medida de combate e/ou prevenção contra carrapatos reduziram a chance dos cães serem expostos aos organismos do GFM, sendo assim considerados fatores de proteção. Em relação 
à faixa salarial do responsável pelo animal, possuir renda entre dois e quatro salários mínimos foi identificado como fator de proteção significativo $(\mathrm{p}<0,05)$, contudo, acima de quatro salários mínimos não foi encontrada significância. A faixa etária não foi significativa na presença das demais variáveis analisadas.

\section{DISCUSSÃO}

Muitos autores têm relatado a presença de anticorpos anti-Rickettsia spp. em cães na região sudeste do Brasil. No estado de São Paulo (SP), Lemos et al. (1996) observaram que em área endêmica para FMB 36,4\% dos cães apresentaram reação sorológica anti- $R$. rickettsii, enquanto em área não endêmica, 12,9\% dos cães apresentaram-se reagentes. Ainda em SP, Horta et al. (2007) e Pinter et al. (2008) observaram, respectivamente, $60 \%$ e $64 \%$ de cães reativos na sorologia anti- $R$. rickettsii e outras espécies.

Era esperado que o número de cães reagentes pela IFI fosse menor no presente estudo do que em SP, uma vez que este último possui o maior número de casos humanos registrados de FMB, sugerindo que a circulação de espécies do GFM seja maior em SP do que no RJ. Contudo, no município de Resende-RJ, onde ocorreu surto de FMB com morte, $28,1 \%$ dos cães testados foram reativos na pesquisa de anticorpos anti- $R$. rickettsii (Cunha et al. 2014). Resultados ainda mais elevados $(58,7 \%)$ foram encontrados em cães do Vale do Paraíba, estado do RJ (Gazeta et al. 2009). Embora a ocorrência da doença humana no estado do RJ seja baixa, a realização de inquéritos sorológicos em cães é importante na epidemiologia da FMB, conforme sugerido por Scorpio et al. (2008), os quais afirmaram que a chance de contato com Rickettsia spp. é maior em cães do que em humanos, uma vez que os cães estão em maior contato com os vetores competentes. Tais achados permitiram inferir que muitos fatores podem estar relacionados à frequência de cães reagentes nos testes sorológicos como a espécie envolvida na resposta antigênica, localidade do estudo e a proximidade com áreas de surtos humanos da FMB.

Como não houve diferença significativa entre os animais reagentes de acordo com as UC, os resultados sugeriram que espécies do GFM estão presentes em todas as UC avaliadas. Silveira \& Fonseca (2011), avaliando ambientes com potencial para a ocorrência de carrapatos vetores, relataram que a interação humana com o meio ambiente, seus animais domésticos e silvestres podem representar risco para a saúde humana. Tal fato está de acordo com o presente estudo, o qual revelou que houve evidência de exposição aos agentes do GFM em cães no entorno de todas as UC estudadas e que houve maior frequência de reação sorológica na IFI entre os cães com hábito de frequentar áreas de mata, pastagem e coleções hídricas no interior das UC, quando comparados aos cães sem acesso aos mesmos locais.

Embora seja descrito que as doenças transmitidas por artrópodes não apresentem predisposição quanto à faixa etária (Ferreira et al. 2012), no presente estudo a frequência de animais reagentes pela IFI foi maior entre os cães com idade de três a sete anos. É possível que os animais adultos sejam mais ativos e por isso frequentem mais ve- zes ambientes propícios aos carrapatos do que as demais faixas etárias. Acredita-se que para uma espécie de vertebrado ser considerada bom hospedeiro amplificador de $R$. rickettsii, ela deve ser abundante em uma área de FMB; ser bom hospedeiro para o carrapato vetor; ser susceptível à infecção por $R$. rickettsii; além de ter alta renovação populacional (Spielman \& Hodgson 2000). Cabe ressaltar que os cães adultos, entre três e sete anos de idade domiciliados nas residências adjacentes às UC estudadas se enquadraram em tais requisitos.

0 presente estudo sugeriu a importância do médico veterinário no combate da exposição de cães à Rickettsia spp., uma vez que a evidência sorológica de infecção por $R i$ ckettsia spp. foi significativamente maior nos cães que não possuíam assistência médico-veterinária regular e que não eram submetidos a nenhuma medida de combate e/ou prevenção contra carrapatos. É possível que os responsáveis pelos cães com assistência veterinária fossem precocemente alertados sobre o perigo das infestações por carrapatos, sobre possíveis zoonoses veiculadas por estes artrópodes e sobre as principais medidas profiláticas e de combate a esses ectoparasitos. A análise multivariada corroborou para tal hipótese, uma vez que o acompanhamento veterinário e as ações contra os carrapatos configuraram fatores de proteção para os cães, reduzindo a chance de exposição à bactéria. Contudo, mais estudos são necessários a fim de esclarecer a verdadeira participação do médico veterinário em ações de Saúde Pública.

De acordo com Cunha et al. (2014), o fato do cão adentrar regiões de mata e pasto influencia positivamente na presença de anticorpos anti-GFM Rickettsiae. Semelhantemente, no presente estudo, cães com este mesmo hábito, mas também que não possuíam acompanhamento regular por um médico veterinário, cujos responsáveis recebiam até dois salários mínimos e cujos responsáveis não adotavam nenhuma medida de combate e/ou prevenção contra carrapatos apresentaram mais chances de exposição aos agentes do GFM quando comparados aos demais cães do presente estudo.

\section{CONCLUSÕES}

Existe circulação de espécies do gênero Rickettsia, em especial do GFM em áreas adjacentes às Unidades de Conservação tanto de Proteção Integral quanto de Uso Sustentável no estado do RJ, a qual foi demonstrada por meio de evidência sorológica em cães pela IFI.

É possível que tanto $R$. rickettsii quanto $R$. parkeri estejam presentes nos locais avaliados, uma vez que os cães apresentaram reação sorológica a ambos os antígenos testados, não sendo possível distinguir a espécie que desencadeou a resposta imune.

Cães que mantinham íntimo contato com áreas de mata, pastagem e coleção hídrica no interior das UC estudadas foram mais expostos aos agentes do GFM exaltando a importância da interação do cão com o ciclo silvestre da bactéria.

Os responsáveis com renda igual ou inferior a dois salários mínimos, que não asseguravam assistência veterinária regular aos seus cães e que não adotavam medidas de combate e/ou prevenção contra carrapatos possibilitaram 
maior chance de exposição dos cães aos patógenos do GFM com potencial zoonótico.

Agradecimentos.- Ao Instituto Chico Mendes de Conservação da Biodiversidade, ao Parque Nacional do Itatiaia, Parque Nacional da Tijuca e Parque Nacional da Serra dos Órgãos, e à ONG Connecta, pelo acesso às instituições e aos animais. Ao Médico Veterinário Matheus D. Cordeiro e ao Laboratório de Doenças Parasitárias da Universidade Federal Rural do Rio de Janeiro pelo fornecimento dos cultivos celulares. À FAPERJ, CNPq e CAPES pelo fomento ao laboratório.

\section{REFERÊNCIAS}

Ayres M., Ayres Júnior M., Ayres D.L. \& Santos A.S. 2007. BioEstat 5.0. Aplicações Estatísticas nas Áreas das Ciências Biomédicas. Ed. Sociedade Civil Mamirauá, Belém. 364p.

Brasil 2015. Sistema de Informação de Agravos de Notificação, SINANWEB. Ministério da Saúde. Secretaria de Vigilância em Saúde. Disponível em $<w w w . s a u d e . g o v . b r / \sin a n>$. Acesso em 21 out. 2015.

Brouqui P., Bacelar F., Baranton G., Birtles R.J., Bjoërsdorff A., Blanco J.R., Caruso G., Cinco M., Fournier P.E., Francavilla E., Jensenius M., Kazar J., Laferl H., Lakos A., Lotric Furlan S., Maurin M., Oteo J.A., Parola P., Perez-Eid C., Peter O., Postic D., Raoult D., Tellez A., Tselentis Y. \& Wilske B. 2004. Guidelines for the diagnosis of tick-borne bacterial diseases in Europe. Clin. Microbiol. Infect. 10(12):1108-1132.

Cardoso L.D., Freitas R.N., Mafra C.L., Neves C.V.B., Figueira F.C.B., Labruna M.B., Gennari S.M., Walker D.H. \& Galvão M.A.M. 2006. Caracterização de Rickettsia spp. circulante em foco silencioso de febre maculosa brasileira no município de Caratinga, Minas Gerais, Brasil. Cad. Saúde Pública 22(3):495-501.

Chapman A.S., Murphy S.M., Demma L.J., Holman R.C., Curns A.T., Mcquiston J.H., Krebs J.W. \& Swerdlow D.L. 2006. Rocky Mountain spotted fever in the United States, 1997-2002. Vector Borne Zoonotic Dis. 6:170-178.

Cragun W.C., Bartlett B.L., Ellis M.W., Hoover A.Z., Tyring S.K., Mendoza N., Vento T.J., Nicholson W.L., Eremeeva M.E., Olano J.P., Rapini R.P. \& Paddock C.D. 2010. The expanding spectrum of eschar-associated rickettsioses in the United States. Arch. Dermatol. 146:641-648.

Cunha N.C., Lemos E.R.S., Rozental T., Teixeira R.C., Cordeiro M.D., Lisbôa R.S., Favacho A.R., Barreira J.D., Rezende J. \& Fonseca A.H. 2014. Rickettsiae of the Spotted Fever group in dogs, horses and ticks: an epidemiological study in an endemic region of the State of Rio de Janeiro, Brazil. Revta Bras. Med. Vet. 36(3):294-300.

Estripeaut D., Aramburu M.G., Saez-Llorens X., Thompson H.A., Dasch G.A., Paddock C.D., Zaki S. \& Eremeeva M.E. 2007. Rocky Mountain spotted fever, Panama. Emerg. Infect. Dis. 13:1763-1765.

Ferreira M.R.A., Freitas-Filho E.G., Dias M. \& Moreira C.N. 2012. Prevalência, Fatores De Risco E Associações Laboratoriais Para Erliquiose Monocítica Canina. Enciclopédia Biosfera 8(15):1345-1356.

Gazeta G.S., Souza E.R., Abboud-Dutra A.E., Amorim M., Barbosa P.R., Almeida A.B., Gomes V., Gehrke M.T., Marrelli M.T. \& Schumaker T.T.S. 2009. Potential vectors and hosts of Rickettsia spp.: epidemiological studies in the Vale do Paraíba, state of Rio de Janeiro/Brasil. Eur. Soc. Clin. Microbiol. Infect. Dis. 15(Suppl.2):269-270. (Journal Compilation)

Horta M.C., Labruna M.B., Pinter A., Linardi P.M. \& Schumaker T.T.S. 2007. Rickettsia infection in five areas of the state of São Paulo, Brazil. Mem. Inst. Oswaldo Cruz 102(7):793-801.

Hun L., Cortes X. \& Taylor L. 2008. Molecular characterization of Rickettsia rickettsii isolated from human clinical samples and from the rabbit tick Haemaphysalis leporispalustris collected at different geographic zones in Costa Rica. Am. J. Trop. Med. Hyg. 79:899-902.

Kaskas N.M., Ledet J.J., Wong A., Muzny C.A., Elopre L. \& Hughey L. 2014. Rickettsia parkeri: Eschar diagnosis. J. Am. Acad. Dermatol. 71(3):e87-e89.

Labruna M.B., Horta M.C., Aguiar D.M., Cavalcante G.T., Pinter A., Gennari S.M. \& Camargo L.M. 2007.Prevalence of Rickettsia infection in dogs from the urban and rural areas of Monte Negro municipality, western Amazon, Brazil. Vector Borne Zoonotic Dis. 7:249-255.
Lemos E.R.S., Alvarenga F.B., Cintra M.L., Ramos M.C., Paddock C.D., Ferebee T.L., Zaki S.R., Ferreira F.C., Ravagnani R.C., Machado R.D., Guimarães M.A. \& Coura J.R. 2001. Spotted fever in Brazil: a seroepidemiological study and description of clinical cases in a endemic área in the state of São Paulo. Am. J. Trop. Med. Hyg. 65(4):329-334.

Lemos E.R.S., Machado R.D., Coura J.R., Guimarães M.A.A.M. \& Chagas N. 1996. Epidemiological aspects of the Brazilian Spotted Fever: Serological survey of dogs and horses in an endemic area in the state of São Paulo, Brazil. Revta Inst. Med. Trop. 38(6):427-430.

Milagres B.S., Padilha A.F., Barcelos R.M., Gomes G.G., Montandon C.E., Pena D.C.H., Bastos F.A.N., Silveira I., Pacheco R., Labruna M.B., Bouyer D.H., Freitas R.N., Walker D.H., Mafra C.L. \& Galvão A.M. 2010. Rickettsia in synanthropic and domestic animals and their hosts from two areas of low endemicity for Brazilian Spotted Fever in the Eastern of Minas Gerais, Brazil. Am. J. Trop. Med. Hyg. 83(6):1305-1307.

Pacheco R.C., Moraes-Filho J., Guedes E., Silveira I., Richtzenhain L.J., Leite R.C. \& Labruna M.B. 2011. Rickettsial infections of dogs, horses and ticks in Juiz de Fora, southeastern Brazil, and isolation of Rickettsia rickettsii from Rhipicephalus sanguineus ticks. Med. Vet. Entomol. 25(2):148-155.

Paddock C.D., Finley R.W., Wright C.S., Robinson H.N., Schrodt B.J., Lane C.C., Ekenna O., Blass M.A., Tamminga C.L., Ohl C.A., McLellan S.L., Goddard J., Holman R.C., Openshaw J.J., Sumner J.W., Zaki S.R. \& Eremeeva M.E. 2008. Rickettsia parkeri rickettsiosis and its clinical distinction from Rocky Mountain spotted fever. Clin. Infect. Dis. 47:1188-1196.

Parola P., Paddock C.D., Socolovschi C., Labruna M.B., Mediannikov O., Kernif T., Abdad M.Y., Stenos J., Bitam I., Fournier P.E. \& Raoult D. 2013. Update on Tick-Borne Rickettsioses around the World: a geographic approach Clin. Microbiol. Rev. 26(4):657-702.

Pinter A., Horta M.C., Pacheco R.C., Moraes-Filho J. \& Labruna M.B. 2008. Serosurvey of Rickettsia spp. in dogs and humans from a endemic area for Brazilian spotted fever in the State of São Paulo, Brazil. Cad. Saúde Pública 24:247-252.

Portillo A., García-García C., Mercedes Sanz M., Santibáñez S., Venzal J.M. \& Oteo J.A. 2013. Case Report: A Confirmed Case of Rickettsia parkeri Infection in a Traveler from Uruguay. Am. J. Trop. Med. Hyg. 89:1203-1205

Romer Y., Seijo A.C., Crudo F., Nicholson W.L., Varela-Stokes A., Lash R.R. \& Paddock C.D. 2011. Rickettsia parkeri rickettsiosis, Argentina. Emerg. Infect. Dis. 17(7):1169-1173.

Sabatini G.S., Pinter A., Nieri-Bastos F.A., Marcili A. \& Labruna M.B. 2010. Survey of ticks (Acari: Ixodidae) and their Rickettsia in an Atlantic Rain Forest Reserve in the State of São Paulo, Brazil. J. Med. Entomol. 47(5):913-16.

Sampaio I.B.M. 1998. Estatística Aplicada à Experimentação Animal. Fundação de Ensino e Pesquisa em Medicina Veterinária e Zootecnia, Belo Horizonte. 221p.

Scorpio D.G., Wachtman L.M., Tunin R.S., Barat N.C., Garyu J.W. \& Dumler J.S. 2008. Retrospective clinical and molecular analysis of conditioned laboratory dogs (Canis familiaris) with serologic reactions to Ehrlichia canis, Borrelia burgdorferi, and Rickettsia rickettsii. J. Am. Assoc. Lab. Anim. Sci. 47(5):23-28.

Silveira A.K. \& Fonseca A.H. 2011. Caracterização de Ambientes com Potencial para Ocorrência de Carrapatos Transmissores de Agentes Patogênicos para Humanos. Boletim do Parque Nacional do Itatiaia. Vol.13. Instituto Chico Mendes de Conservação da Biodiversidade. 106p.

Spielman A. \& Hodgson J.C. 2000. The natural history of ticks: a human health perspective, p.1-13. In: Cunha B.A. (Ed.), Tickborne Infectious Diseases. Diagnosis and Management. CRC Press., New York.

Spolidorio M.G., Labruna M.B., Mantovani E., Brandão P.E., Richtzenhain L.J. \& Yoshinari N.H. 2010. Novel Spotted Fever Group rickettsiosis, Brazil. Emerg. Infect. Dis. 16(3):521-23.

Whitman T.J., Richards A.L., Paddock C.D., Tamminga C.L., Sniezek P.J., Jiang J., Byers D.K. \& Sanders J.W. 2007. Rickettsia parkeri infection after tick bite, Virginia. Emerg. Infect. Dis. 13(2):334-336.

Zar J.H. 1999. Biostatistical Analysis. 4th ed. Prentice Hall, Upper Saddle River, p.486-500. 